\title{
Barthes editor de moda
}

RESUM0: Foi observando revistas e catálogos da alta moda que Barthes escreveu "O Sistema da Moda". Esta curiosa análise levou à descoberta de novas simbologias e à criação de sistema original que identifica estruturas no espaço entre a roupa e a moda. Segundo o semiólogo, a moda tende a "recitar o vestuário mais do que fabricá-Io". Com a massificação do fast fashion, um dos maiores símbolos são as $t$-shirts estampadas com frases. A letra estampada sobre a camiseta é hoje uma das peças de roupas mais vestidas no mundo. Teria Barthes, ao enunciar a já citada afirmação, antecipado uma importante tendência de estilo que perdura desde o fim do século passado? Ao analisar o tecido, Barthes exalta na práxis do vestir o aparecimento do sentido. Ao vestir um casaco, por exemplo, este estaria assumindo o lugar da pessoa. São estes alguns dos pontos que constituem este trabalho.

PALAVRAS-CHAVE: Consumo; Vestuário; Fast-fashion; Moda; Fashion-victims; Normcore.

\section{Barthes, fashion editor}

ABSTRACT: Roland Barthes wrote The fashion system based on fashion magazines. This different analysis led to the discovery of new symbols in the space between clothing and fashion. According to Barthes fashion tends to describe and legislate more than manufacture clothing. Within the clothing mass production and the appearance of the fast-fashion, one of its great symbols are the $T$-shirts with printed phrases on it. These items areinclusive one of the best-selling clothing in the world. Would have Barthes, with that evoked statement regarding the power of fashion to describe and legislate clothing, foreseen a major fashion trend that lasts through the last century? By analyzing the fabric, Barthes points out the emergence of the meaning that permeates the dressing praxis. Wearing a jacket, for instance, would mean the object taking the person's place. These are some aspects that are discussed in this paper.

KEYWORDS: Consumption; Clothing; Fast-fashion; Fashion; Fashion-victims; Normcore.

\section{Introdução}

0 vestir salvou a humanidade do frio e do pudor. Cobrimos o corpo de muitos argumentos: um dia ele pode ser clássico e em outro, casual. Por muito tempo o espaço reservado para a palavra era restrito ao nome da marca e pelo avesso com as instruções de lavagens. Hoje, a palavra está estampada, bordada, enfim, recortada explicitamente no vestuário.

A moda parece defender que as pessoas entendam o que estão vestindo, mas este olhar pode ser desviado pelo adjetivo da roupa: "Este belo vestido", "linda blusa", "bonita saia" são referenciadas como se substituíssem a função da roupa. A pergunta "você tem estilo?" em algum momento nos incomodou com a resposta que veio depois: "0 meu estilo é uma maneira de expressão"?. Vestir é responder? A expressão do homem não é apenas composta por palavras, mas evidenciada.

A primeira frase da jornada barthesiana na moda é significativa: "Abro uma revista de Moda: vejo" (BARTHES, 2009, p.19). Ao abrir a revista e ser tomado por imagens e textos que informam tais novidades, Barthes buscou o espaço onde o vestuário pudesse ser vestido e compreendido a partir de outras relações. E foi na superfície descritiva que encontrou sua obra. o Sistema da Moda possui estrutura narrativa muito peculiar. Para analisar a moda, Barthes opta por analisar a parte textual das revistas. É um trabalho polêmico: 0 autor demorou dez anos

\footnotetext{
${ }^{1}$ Graduada em Estilismo (Universidade Candido Mendes) e Design de Moda (Universidade Salgado de Oliveira). Pós-graduanda em Roteiro para Cinema e TV na Universidade Veiga de Almeida (UVA). E-mail: salmasoria@gmail.com.
} 
para publicar o estudo e passou a negar a obra após a publicação ${ }^{2}$. Curiosamente, a negação da moda é elemento abordado por Barthes como própria razão de moda:

\begin{abstract}
Assim que o significado moda encontra um significante (tal vestuário), o signo se torna a moda do ano, mas por isso mesmo, essa moda recusa dogmaticamente a moda que a precedeu, ou seja, seu próprio passado; toda moda nova é recusa a herdar, subversão contra a opressão da moda antiga. (BARTHES, 2009, p. 402)
\end{abstract}

0 que fez Barthes, em 0 Sistema da Moda, ser editor de moda?

Seria muito simples resumir que Roland Barthes anteviu vários tipos de modismos. Mais do que isso, dialogou comestruturas da moda, apontou movimentos através da linguagem,além de detectar no campo da imagem edarealidade vetores fundamentais, criando assim outras simbologias que são perfeitamente atuais.

Barthes decifrou os enunciados das revistas francesa Ellee Lejardin des Modes entre 1957 e 1958. 0 contexto histórico é o seguinte: Barthes começou o estudo em 1957; por isso podemos observar que os enunciados estudados no livro ficam em torno da estética de cintura marcada, saia abaixo do joelho e uso de chapéus e luvas. 0 vestuário global era dominado pelas criações do Monsieur Dior, criador do New Look, roupa importante para feminilizar a mulher do pós-guerra. Quando Barthes publicou o estudo, Monsieur Dior estava morto havia nove anos, e a Maison era comandada pelo jovem Yves Saint Laurent, famoso por colorir o vestuário e mudar radicalmente a direção artística da Dior. A minissaia já era uma realidade na sociedade.

Como falar de 0 Sistema da Moda hoje? Com sociedades cada vez mais híbridas, a revista invade as ruas e as ruas invadem as revistas. Vide a histórica capa da revista Elle Brasil, em Maio de 2015. A capa não reproduz nenhum rosto ou moda. Apenas uma superfície espelhada que reflete a imagem de quem olhar para a capa. 0 slogan é simples e não menos poderoso: "Você na capa".

Neste sentido é que este artigo empreende uma investigação semelhanteà de Barthes; Ora, propomos analisar os mesmos enunciados vistos por Barthes não somente de dentro da revista, mas aquele que tomam o campo dosenunciados nos vestuários das ruas. Com isso, pode-se dizer que o resultado da pesquisa aponta que o sistema de Barthes tem seu sentido ampliado. O Sistema da Moda está diretamente ligado à expressão das roupas que as pessoas consomem nas ruas de hoje.

\title{
2. Os três vestuários barthesianos e a função parasita
}

No Sistema da Moda, há três vestuários: imagem, realidade e a estrutura verbal. 0 vestuário imagem "conserva um valor que pode perturbar consideravelmente sua análise: a plástica" (BARTHES, 2009, P.27). A comunicação fotográfica está voltada para a roupa. No entanto, a imagem não possui a mesma relação com o objeto fotografado no sentido de igualdade material, forma, cor e superfície. Toda essa unidade fotográfica aponta para a roupa mas essa totalidade não é a roupa em si.

Por sua vez, o vestuário real: "Para analisar o vestuário real em termos sistemáticos (...) seria preciso remontar aos atos que orientaram sua fabricação (...). Tem-se uma estrutura que se constitui no nível da matéria e de suas significações" (BARTHES, 2009, p.22). Assim é que Barthes, embora precisasse do vestuário para decodificar o sistema da moda, não se debruça sobre a confecção e a origem da roupa. De maneira sagaz, o crítico percebe na revista de moda o auge da divulgação do sistema e assume o itinerário da leitura e o não da avaliação plástica, análise técnica ou funções práticas.

\footnotetext{
${ }^{2}$ Em entrevista ao jornal Le Monde de 19/ 04/ 1967 e republicada no livro Roland Barthes inéditos vol. 3 Imagem e Moda (2005) Barthes alerta: "Por mais limitado que seja esse livro sobre a moda, ele formula 0 problema de saber se existe um objeto que se chama vestuário de moda" (2005, p. 376) e "Minha pesquisa, deste ponto de vista, tem um aspecto um tanto ingênuo" (2005, p. 380).
} 
É assim, pois, que ele define o vestuário linguagem, instância que o interessa:

Somente o vestuário escrito não tem nenhuma função prática ou estética: ele é inteiramente constituído em vista de uma significação. [...] 0 ser do vestuário escrito está inteiramente em seu sentido. [...] Não é perturbado por nenhuma função parasita" (BARTHES, 2009, p.27).

Sob a ótica vestuário-descrito-na-revista: a moda é estável. A forma da investigação de Barthes poderia ate gerar controvérsias pois é de se questionar como o fazer de uma costureira, modelista ou estilista não foram observados de frente, mas o caráter das significações são válidas até hoje: Qualquer designer, produtor, fotografo, repórter ou outro profissional da moda almeja trabalhar/aparecer em revista de moda como reconhecimento de seu trabalho. Uma vez reconhecido na revista, aquilo é validado como moda. Certa vez Barthes (1991, p. 77) descrevera na obra Mitologias que a revista ELLE é um verdadeiro tesouro mitológico.

0 fazer da costura, modelagem, criação e desenvolvimento da moda são linguagens encontradas na revista. Se os três vestuários fossem estudados ao mesmo tempo, além de ato instável, cada uma dessas estruturas, ao se mesclarem, comporiam um objeto genérico chamado vestuário de moda por comodidade, onde a função parasitária seria mais importante que a significação (BARTHES, 2009, p. 26). A função parasita no vestuário real, por exemplo, pode ser identificada através do significado-função da roupa: na finalidade de proteger, adornar ou na relação de pudor.

0 excesso da oferta de consumo no vestuário transforma a função parasita da roupa em ação oculta. Vemos o uso de casacos no verão, maiôs no inverno sendo usados pela síntese de ser 'bonito' ou 'tendência'. Há instabilidades e paradoxos no vestuário real.A função parasitária do vestuário imagem está na tensão de incorporar toda a mensagem através de uma única imagem.É por esta razão que Barthes deixa de lado tais estruturas para se concentrar apenas na última camada, a da moda no nível verbal:

\begin{abstract}
0 vestuário tratado pela revista de moda tem uma vantagem metodológica imediata em relação à análise do vestuário real: o vestuário "impresso" oferece ao analista aquilo que as línguas humanas negam ao linguista: uma sincronia pura; [...] 0 vestuário escrito não é perturbado por nenhuma função parasita e não comporta nenhuma temporalidade vaga: por essas razões, optamos por explorar a estrutura verbal. (BARTHES, 2009, p. 26-27)
\end{abstract}

0 vestuário barthesiano habita na linguagem e não se resume a uma simples interpretação de imagem ou estrutura da frase pois "a estrutura do vestuário escrito não pode confundir-se com a estrutura da frase; pois, se o vestuário coincidisse com o discurso, bastaria mudar um termo desse discurso para mudar a identidade do vestuário descrito". (BARTHES, 2009, p. 20-21). Exemplificando: Barthes toma esta frase: "Para o almoço festivo em Deauville, corpete macio"3 (2009, p. 43). Ao substituir a palavra "almoço" pela palavra "café" obtem-se a seguinte frase: Para o café da manhã festivo em Deauville, corpete macio. $\mathrm{E}$, em seguida, substituir outra palavra, dessa vez, "festivo". A frase fica assim: "Para o almoço de negócios em Deauville, corpete macio". No entanto, como Barthes observou, a identidade do vestuário não muda com a troca da frase. 0 corpete não deixa de ser macio, nem deixa de ser corpete (embora seja divertido imaginar uma senhora vestindo um corpete numa reunião de negócios). Como se percebe, não é no nível da frase que Barthes coloca a questão, mas no nível da significação.

Assim, ainda que o modelo transmitido pelo vestuário imagem e vestuário escrito sejam sínteses do vestuário real, a leitura é uma decodificação precisa da descrição de moda. A descrição registra o desvendamento do vestuário: "Quanto mais vestidos

\footnotetext{
${ }^{3}$ Esta frase surge recortada pela primeira vez no capítulo 2 onde Barthes analisa a relação de sentidos.
} 
fotografados eu vejo, mais se banaliza a informação que recebo: a nota falada ajuda a revigorar a informação" (BARTHES, 2009, p.38).

\section{0 recitar no vestuário}

A moda tende a 'recitar' o estuário mais do que fabricá-lo. (BARTHES, 2009, p. 274)

Se o século passado foi importante para as mulheres usarem calças e minissaias, este século é responsável por tornar o verbo, roupa. Em poucos minutos caminhando pela cidade podemos perceber que a $t$-shirt com frases estampadas é uma das peças mais vestidas no cotidiano. Poderiam ser enormes cartazes escritos, mas são roupas que tomam o seu lugar transformando a ação do vestir em suporte para divulgação dessas mensagens. Às vezes possuímos a discreta dúvida se algumas dessas pessoas realmente entenderam as mensagens das roupas que estão usando.

Roupas são emojis - figuras - de celular, pequenos ícones que recitam a ação do vestir, numa espécie de trompe l'oeil digital. É possível, através do recurso de envio de mensagens instantâneas, explicitar que algo dentro do sentido do vestuário está ocorrendo. Padrões estéticos podem ser medidos através do vestuário das sociedades e as $t$-shirts tem papel fundamental na condução da semiótica barthesiana da moda.

Quando nos deparamos com certas mensagens transmitidas por $t$-shirts ficamos sem entender a lógica de certos elementos. Curiosamente, o Sistema da Moda pode ter desvendado suas significações.Barthes divide os enunciados do vestuário em dois grupos: conjuntos $\mathrm{A}$ e $\mathrm{B}$. Em relação às estampas das camisetas,identificamos que elas possuem mensagens diretas e indiretas. Nesta lógica, seguindo a análise traçada por Barthes, podemos traçar a seguinte relação:

\section{Conjunto de sistemas A: 0 mundo}

Possui relação explícita com o mundo. Seus enunciados são explícitos e capazes de produzir importantes contribuições na história da moda, sobretudo para a cultura jovem e política: "o enunciado do significado será constituído por todos os traços mundanos contidos num único enunciado da significação" (BARTHES,2009, p.96).

1976: Nove anos após o lançamento de O Sistema da Moda (e vinte da morte de Monsieur Christian Dior), Malcolm MacLaren em Londres, influenciado pelos movimentos estudantis anárquicos oriundos da França, precisava falar para o mundo o que sentia e ao lado da namorada (chamada Viviene Westwood) criaram uma camisa que mudaria completamente os rumos da moda. Era feita de algodão barato e podiam ser vistos na camisa não apenas o botão, os pespontos ou a gola, mas as frases: "Only the anarchists are pretty" $e$ "Try the subversion". A imagem de Karl Marx localizada do lado esquerdo se justificava porque Marx vivera em Londres em uma determinada época, num evidente reconhecimento do sentido mundano de sua significação. Pode-se dizer que a partir dessa camisa a massificação da frase estampada na roupa foi evidenciada na cultura jovem.

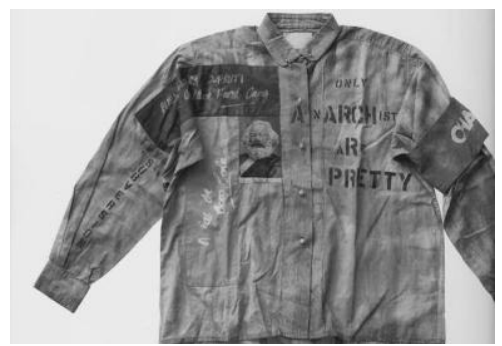

Imagem 1: Camisa criada por Malcolm MacLaren e Viviene Westwood.

Fonte: Site Paul Gorman, 2014 
Do que seria o movimento punk sem as frases de camisas? Poderiam escrever cartazes? Grafitar muros? Sim, mas decidiram usar a roupa como suporte assumindoa explícita relação entre vestuário e mundo. Barthes (2009, p.83) antecipa que "o sentido indumentário (a própria finalidade do enunciado) é estreitamente dependente do nível verbal".

Em 1983, a estilista Katherine Hammett encontrou Margareth Tatcher numa cerimônia de gala em meio a uma grande polêmica: Tatcher apoiava a política de guerra norte-americana deixando que mísseis guiados ficassem estacionados na Grã Bretanha, apesar da maioria da sociedade britânica ser contra. A estilista não perdeu a oportunidade de vestir seu recado. Maxi $t$-shirt de algodão com a estampa " $58 \%$ não querem Pershing".Barthes (2009, p.46) observara que "nem o vestuário nem o mundo jamais estão desprovidos de uma expressão verbal".

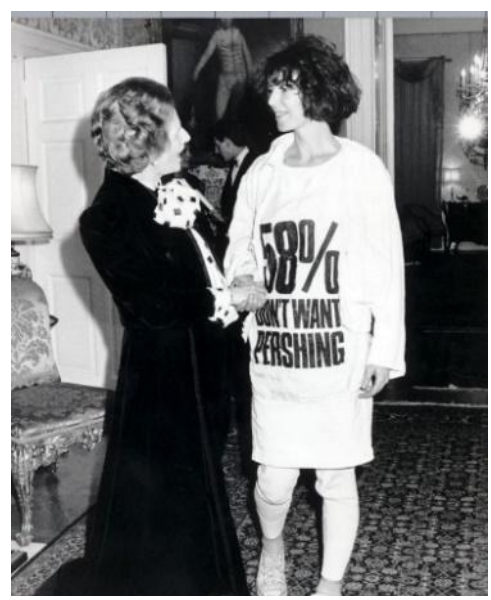

Imagem 2: Katharine Hammett e sua t-shirt encontram Margareth Tatcher. Fonte: Site Iconic Photos 2010

\section{Conjunto de sistemas B: Vestuário tem a moda como função}

É um sistema moderno, que antecipa o que viria a ser necessário para a massificação da moda: o surgimento da "tendência". 0 sistema B possui relação dependente da moda, ou seja, é a significante do significado. Representa a moda no mundo daquele momento, vivenciada como uma instância superior tirânica. Ignora-se o mundo real. A descrição acompanha uma fotografia ou uma receita. E é dessa referência exterior que ela de fato extrai sua unidade estrutural.

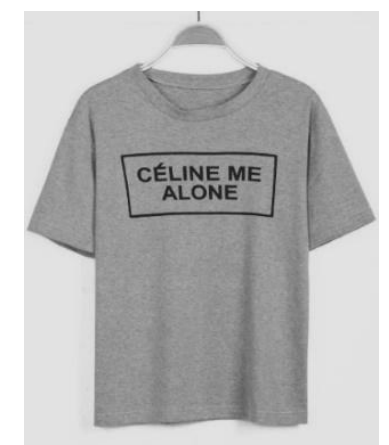

Imagem 3: T-shirt em algodão mescla, estampa Céline Me Alone.

Fonte: Site She In, 2013

A frase da camiseta refere-se ao mundo da grife francesa Céline em analogia à frase "Leave me alone". Aqui é Céline-me alone e basta. Sem dúvida esta camiseta carrega uma promessa que deixaria qualquer blogueira fashion excitada. 


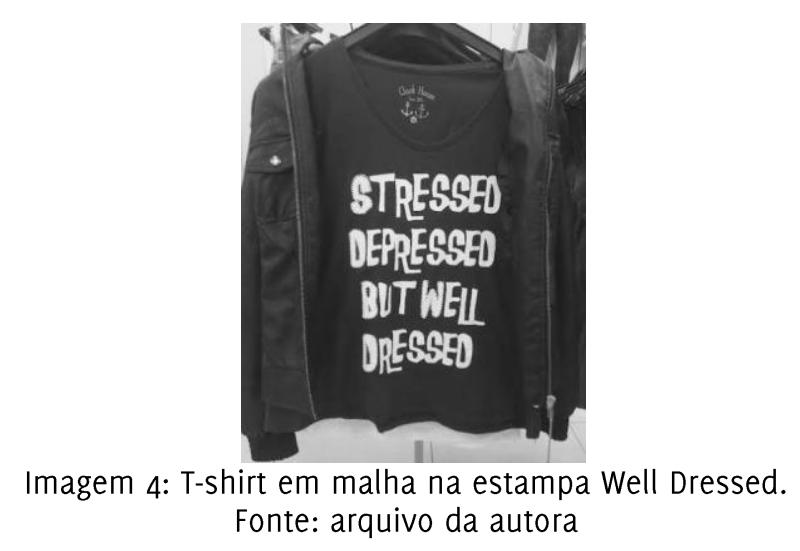

A frase da camiseta diz "estressada, deprimida, mas bem vestida". Não saberemos quais foram os motivos da conclusão tão dramática, mas a mensagem certamente narra um poderoso final reforçando o papel ideológico da moda: estar bem vestida.

Estas camisetas ignoram 0 vestuário real. Não apenas por conter enunciados desconectados da realidade, mas também por conter descrições inverossímeis: 0 enunciado da camiseta Céline não foi criado pela grife francesa e sim por uma empresa americana de $t$-shirts que não proporcionaria aos seus clientes a real experiência de "celinizar-se" por inteiro. A segunda camiseta elenca os motivos de estar numa má fase, porém, bem vestida. Todos os sentidos são de transitoriedade. Sozinha, a camiseta de malha não torna ninguém bem vestida. No máximo, confortável.

Embora desconectados, estes enunciados estão dispostos numa variante popular (camiseta) para se tornar elemento de moda pura ao invadir as cidades, exercendo seu papel de despertar na maioria das pessoas a curiosidade e a reflexão sobre a descrição estampada: aquilo pode ser seu.

\section{A costumização se aproxima do shifter}

A costumização(não enquanto técnica de costura, mas no sentido da palavra) é vetor presente dentro do vestuário real barthesiano. Neste léxico, o vestuário real só pode ser representado na moda por meio de shifters, que em livre tradução significa algo que será transformado. Toda porção de descrição indumentária vem da "língua" introduzida por um shifter.0 processo de costumização baseia-se na personalização da roupa e é território livre entre imagem, linguagem e realidade.

0 vestuário verbal só pode ser transformado em representação por meio de alguns operadores que poderiam ser chamados de shifters pois servem para transpor uma estrutura para outra, ou digamos, passar de um código para outro. (BARTHES, 2009, p.23)

Os shifters são:

REAL IMAGEM: reproduz analiticamente os atos de fabricação do vestuário (BARTHES 2009, p.24) 


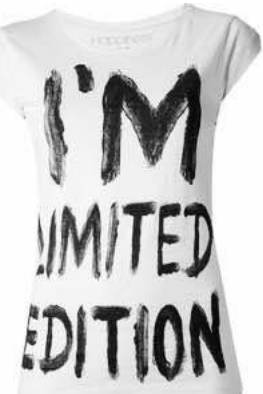

Imagem 5: Camiseta de malha estampada limited edition.

Fonte : Site Shopbop, 2014

A camiseta branca é interferida por letras gigantes pintadas à mão que declaram "Eu sou edição limitada". A descrição torna explícita a raridade da peça. Estes são elementos presentes na costumização.

REAL__LINGUAGEM: Constitui uma linguagem transitória situada entre o fazer e o ser, a origem e a forma, a técnica e o significado do vestuário. (BARTHES, 2009 p.24).

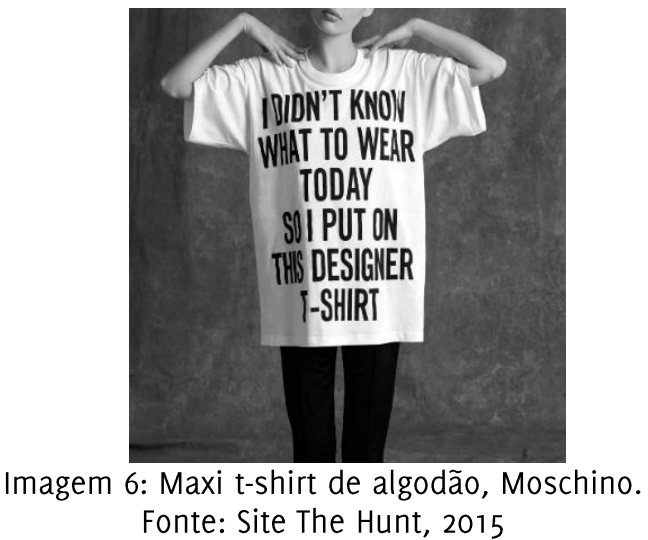

Em livre tradução: "Eu não sei o que vestir hoje. Então eu coloquei esta t-shirt de designer". Se o termo "designer" sofresse uma modificação e desaparecesse, teríamos eu não sei o que vestir hoje então coloquei esta t-shirt. Mas, como esta camiseta foi produzida por uma famosa grife italiana, o termo promove a validação da prática (ser um produto de design). A estampa assume o lugar da pessoa e descreve uma dúvida de não saber o que vestir, tendo sua dúvida resgatada(e glamurizada) pelo uso da palavra designer. A camiseta reafirma sua origem transitiva em forma (t-shirt), técnica (t-shirt de designer), mas também em seu significado (uma t-shirt para ser usada quando não saber o que vestir).

IMAGEM_LINGUAGEM: Possibilita passar da estrutura icônica à estrutura falada, da representação do vestuário à sua descrição. (BARTHES, 2009 p.25).

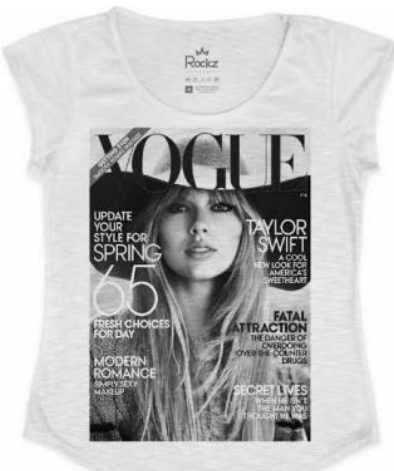

Imagem 7: T-shirt algodão misto estampa capa Vogue.

Fonte: Site Flor e Rosa, 2015 
A camiseta reproduz a capa da Vogue como estampa. Uma ruptura de estrutura que permite transitar entre a imagem e a linguagem.

\title{
7. 0 caso Twin-Set
}

0 próprio ser do Twin-Set permite significar a moda (BARTHES, 2009, p. 141).

Ao analisar OSV (Objeto, Suporte e Variante) Barthes observou que certos tipos de combinações e desdobramentos causados em virtude destas associaçõesnecessitam da moda e a moda, por sua vez, necessita delas para validar sua ações. É o caso do Twin-Set. Não sendo apenas um peça de roupa sobre outra peça de roupa.

Em Barthes, o vestuário afirma para significar. Não é a matéria do twin-set que sofre variação, mas a indumentária em relação á língua. Se retirarmos um elemento deste tipo de vestuário o ser do twin set é eliminado, restando apenas o signo blusa ou cardigan.

\section{Signo da competição}

Flügel em "A psicologia das roupas", livro também estudado por Barthes, não tinha dúvidas de que a essencialidade da moda residia na competição social e sexual, sendo o social a instância mais evidente e o caráter sexual sendo mais disfarçado e escondido no modo social (FLÜGEL, 1966, p.126).

Nesta competição social, a intenção da vítima da moda é deixar de ser alguém "comum", vestindo todos os modismos imediatos. A retórica de Barthes acontece na fashion victim ao vestir várias contradições com extrema eloquência. Se na estação passada ela estava entre 0 pop art e o neo minimal, nesta estação ela pode vestir o militarismo, animal print e um pouco de transparências porque afinal, isto está em voga.A classificação do alguém 'comum' e da vítima da moda são interessantes de serem analisados em Barthes porque servem de contraponto: de um lado a sobriedade urbana e de outro a opulência alegórica.

\begin{abstract}
Decorrem dois sonhos, que a retórica de Moda põe ao alcance da mulher: identidade e jogo. 0 sonho de identidade (o de sermos nós mesmos, de obtermos 0 reconhecimento dos outros) parece encontrar-se em todas as obras de massa e em todos os mínimos comportamentos daqueles que delas participam, quer nisso se veja uma conduta de classes alienadas, quer se descubra um ato compensatório destinado a reagir contra a "despersonalização" da sociedade de massas; em todo 0 caso, o sonho de identidade se exprime essencialmente pela afirmação do nome, como se o nome realizasse magicamente a pessoa (BARTHES, 2009, p.378).
\end{abstract}

Há quem fuja do vestir as últimas novidades preferindo usar jeans, camiseta e tênis, sendo Mark Zuckerberg e Steve Jobs os maiores ícones. A moda hoje assiste ao normcore: em resumo, alguém que não se importa com a moda vestindo o básico e é o extremo oposto da vítima da moda. 0 termo normcore foi a palavra (na categoria moda) mais pesquisada no google durante todo o ano de 2014.

Certamente Barthes não sabia o que era um normcore e ele mais uma vez, antecipa esse olhar ao classificar signos e funções do vestuário real ao discorrer que uma roupa normal, "comum" só existiria dentro do sistema da moda como elemento de oposição em razão da padronização de seus objetos.

O paletó "esporte" já não tem função esportiva, mas só existe como signo, em oposição ao formal; o macacão de trabalho (blue-jean) tornou-se signo do ócio etc. Esse processo de significação é mais forte quando a sociedade multiplica seus objetos padronizados: ao enriquecer seu sistema diferencial de formas, ela favorece o nascimento de léxicos de objetos, cada vez mais complexos: é o que explica o fato de a sociedade moderna, tecnológica, poder 
facilmente separar o signo da função e permear com significações variadas os objetos utilitários que fabrica (BARTHES, 2009, p. 391)

\section{A imagem da infidelidade}

Em certo momento da obra, o autor fala da "neurose da Moda. Mas essa neurose se incorpora numa paixão progressiva, a fabricação do sentido: a moda só é infiel quando burla o sentido" (BARTHES, 2009, p. 426).

Com os lançamentos cada vez mais acelerados, a moda incita seu público a vestir as últimas novidades.

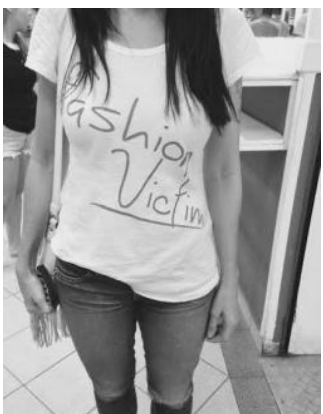

Imagem 10: Estudante veste camiseta fashion victim.

Fonte: arquivo da autora.

Primeiro me deparei com a imagem desta camiseta no corredor da faculdade em horário de almoço. E como numa lógica feita de zoom out fui ampliando a imagem. 0 que despertou atenção é que a dona da camiseta, uma moça de 23 anos,não parecia ter se dado conta da expressão que carregava: Fashion Victim. Permitiu a investigação em torno da camiseta, mas sem ser identificada. Ao ser perguntadasobre os motivos de escolha da $t$ shirt, a resposta foi rápida: "Porque é basica. Gosto dela".Embora para a jovem a camiseta tenha apenas o significado de neutralidade, a significante parece pular na frente dela e apontar, grifar (a camiseta possui mesmo um grifo no fim da palavra) esta é uma vítima da moda. Algo curioso a ser analisado: a composição de suas roupas. Vestia jeans e camiseta. Seu estilo poderia ser classificado como normcore? Mas, as palavras da t-shirt gritam e empurram a moça num dilema, eliminando qualquer oportunidade de defesa: a quem ela trai? Ao normcore ou ao fashion victim? Seria ela tão fashion victim que decidiu aderir ao normcore apenas por ser a moda do momento? Ou tão normcore que não percebeu 0 significado da mensagem estampada? Em Barthes ela burlou o sentido: "A mulher da moda sonha ao mesmo tempo em ser ela mesma e em ser outra" (BARTHES, 2009, p. 379).

Hoje pouco se discute a vitimização da moda porque é valor consolidado e impossível de ser removido de dentro do sistema. Todos nós fomos, somos e continuaremos sendo vítimas da própria moda. Todo e qualquer vestuário de nosso armário já foi ou está fazendo parte da tendência de moda (ainda que numa escolha inconsciente). Até mesmo o famoso "jeans e camiseta" da loja de departamento. Eles estão ali não apenas por uma questão comercial, mas pela razão de estar atualizado na moda. Não há como escapar. Uma parte das mulheres compram a última moda com total consciência de seu risco: ficar fora-demoda, gerando a sensível cadeia do entrar-sair da moda.

Vemos a Moda "brincar" com o tema mais grave da consciência humana (Quem sou eu?); mas, por meio do processo semântico ao qual submete, a Moda o marca com a mesma futilidade que lhe permite inocentar sempre a obsessão pelo vestuário, da qual ela vive (BARTHES, 2009, p.380). 


\section{Dress to sucess no Vestema}

A moda não se resume somente em vestir algo e sim anunciar o que vestir, classificar um estilo, uma marca ou um cenário. Vestir-se para o sucesso é sinônimo de aceitação social.

Em 1954, Monsieur Christian Dior publica o livro o Pequeno Dicionário de Moda que prega três elementos principais: simplicidade, elegância e bom gosto (DIOR, 2009). Barthes, em 0 Sistema da Moda, vê no enunciado três elementos principais sobre a moda: retórico, terminológico e pseudoreal. Dior classifica estilos, modos de combinar tecidos, como vestir adequadamente, entre outras dicas. Barthes cria para a moda o Vestema, uma variante definidora que exalta através desta simbologia a práxis do vestir.

A variante do Vestema faz do vestuário o próprio sentido. Seus termos não podem ser atualizados simultaneamente: "uma gola não pode ser ao mesmo tempo aberta ou fechada" (BARTHES, 2009, p.174).Ainda que este exemplo ficasse fora do campo verbal, não há como uma gola estar aberta e fechada no mesmo momento. A língua estabelece o norte principal: "uma das funções da linguagem é combater a tirania da percepção visual e ligar os sentidos a outros modos de percepção ou sensação"(BARTHES, 2009, p.184).

Assistimos a massificação de blogs, programas de tevê e resenhas de jornais que pregam o look do dia obsessivamente. Isto fomenta o mercado que bate recordes em vendas e popularidade, pressionando toda a cadeia a expor-se ainda mais. A obra de Barthes lançou uma luz atemporal entre o fazer e o ser da moda.

0 mundo da Moda é o trabalho pelo avesso; uma primeira rede de significados retóricos, compreenderá todas as unidades (e suas metáforas ou parataxes parciais) que tenham relação com o fazer humano, ainda que esse fazer tenha 0 cunho de certa irrealidade; em geral, serão todas as funções e todas as situações que impliquem uma atividade (mesmo ociosa), ou as circunstâncias nas quais se supõe que ela seja exercida (BARTHES, 2009, p.367-368).

0 trabalho pelo avesso da moda: uma simples calça pode conter unidades que explicitam o seu contrário circunstanciada pelas atividades ocultas. 0 consumidor pode vestir, também através do avesso, outras significações (cópia do fast fashion, trabalho escravo, insumos têxteis livremente descartados no meio ambiente, tributo a anorexia, consumo compulsivo entre outros). Existe um ar etéreo entre o ser e o fazer da moda. Algo de incontestável por detrás do signo.

0 signo e a necessidade de repetir o apelo pelo novo faz com o que a cópia sempre retorne (BARTHES,1990, p. 182). A maneira com que Barthes considera a moda é extremamente atual:

0 hoje da Moda é puro, destrói tudo em torno de si, desmente o passado com violência, censura o futuro, desde que esse futuro ultrapasse a estação; por outro lado, cada um desses hojes é uma estrutura triunfante, cuja ordem é extensiva (ou estranha) ao mesmo tempo, de tal maneira que a Moda doma o novo antes mesmo de o produzir e realiza o paradoxo de um "novo" imprevisível, mas legislado; podese dizer, em uma, que a Moda domestica o imprevisto, mas sem lhe subtrair 0 caráter de imprevisto (BARTHES, 2009, p. 425).

\section{Conclusão}

Entre a décadas de 50 e 60 do século passado, a interatividade e o poder da individualidade não eram características marcantes, muito menos a revolução digital. Ainda sim, na ação da leitura barthesiana extrai-se informações fundamentais no entendimento das mensagens de moda presentes até hoje. Nos blogs de street style ou em posts do Instagram,podemos encontrar o que Barthes já chamava de "registros de moda no exato momento em que é anunciado e prescrito" (BARTHES, 2009, p. 401). 
Embora seja possível na vida real desvencilhar o vestuário de toda e qualquer obrigação de estar numa revista de moda, a descrição da roupa é incentivo ao convencimento e pertencimento, gerando moda. Entre as referências cotidianas atreladas as roupas surgem adjetivos como se fossem capazes de substituir a função: "Este belo vestido", "Linda camisa" ou "Bonita gola". Não necessariamente uma roupa é bonita por estar na moda, mas, para a grande massa, a roupa deve ter os motivos da moda por ser "bonita". A função e o compromisso nas revistas de moda são a de utilizar a mensagem em torno do bom gosto. Barthes vê além da linha do bom gosto editorial e nos avisa: Nem tudo o que vestimos é real. Em certas vestes há muito mais de sistemas retóricos do que moda. Para Barthes "a indumentária é uma espécie de texto sem fim" (2005, p. 295).

Decodificar as palavras na moda pode ser um exercício bastante desafiador, mas não menos envolvente. Supõe-se que o melhor vestir coloque qualquer pessoa na moda. Muitas mulheres passaram a ser adoradasapenas pelo o que vestem. Além disso, ainda que uma pessoa não acompanhe moda ela é capaz de ouvir, ler e descrever o modismo de alguma estação ou geração. E o motivo para que isso ocorra é porque as palavras vestem a moda. Sem uma a outra simplesmente não existiria.

Há muito mais do que roupas sendo vestidas todos os dias e em todos os cantos do mundo. Somos capazes de sentir o sistema da moda e de vestirmos os Vestemas, ainda que inconscientemente. A crônica barthesiana que define a moda diz ao mundo implícita (ou explícitamente) o seu segredo.

\section{REFERÊNCIAS}

BARTHES, R. Inéditos vol.3 - Imagem e moda. São Paulo: Editora Martins Fontes, 2005 Mitologias. Rio de Janeiro: Editora Bertrand Brasil, 2001.

- o óbvio e o obtuso: Ensaios críticos III. Rio de Janeiro: Editora Nova Fronteira,

1990.

O Sistema da Moda. São Paulo: Editora WMF Martins Fontes, 2009.

DAZED. Disponivel em: http://www.dazeddigital.com/fashion/article/22964/1/normcore-is-themost-googled-fashion-trend-of-2014. Acesso em: 29/05/15

DIOR, C. O pequeno dicionário de moda. São Paulo: Editora Martins Fontes, 2009.

FLOR E ROSA. Disponível em: http://www.florerosa.com.br/tshirt-vogue-taylor-swift.html. Acesso em: 29/05/15

FLUGEL, J.C. A psicologia das roupas. São Paulo: Editora Mestre Jou, 1966.

ICONIC PHOTOS. Disponível em: https://iconicphotos.wordpress.com/2010/05/10/katharinehamnett-meets-thatcher/. Acesso em: 29/05/15

PAUL GORMAN. Disponivel em: http://www.paulgormanis.com/?p=10869\#more-10869. Acesso em: $29 / 05 / 15$

SHEIN. Disponivel em: http://www.shein.com/Grey-Short-Sleeve-CELINE-ME-ALONE-Print-T-Shirtp-113215-cat-1738.html. Acesso em: 29/05/15

SHOP BOP. Disponível em: https://www.shopbop.com/limited-edition-teehappiness /vp/v=1/1553569834.htm. Acesso em: 29/05/15

THE HUNT. Disponível em: https://www.thehunt.com/the-hunt/smNU5t-i-don't-know-what-towear-today-so-i-put-on-the-designer-shirt. Acesso em: 29/05/15 